\title{
Correction to: Inhibition of Tissue Factor Pathway Inhibitor (TFPI) as a Treatment for Haemophilia: Rationale with Focus on Concizumab
}

\author{
Pratima Chowdary ${ }^{1}$ (D)
}

Published online: 11 June 2018

○) Springer International Publishing AG, part of Springer Nature 2018

\section{Correction to: Drugs \\ https://doi.org/10.1007/s40265-018-0922-6}

Figure 1

The legend, which reads

Mechanisms of action of monoclonal antibodies against tissue factor pathway inhibitor (TFPI)

Should read

TFPI mechanism of action and inhibition by anti-TFPI antibodies. a Tissue factor (TF) based initiation of coagulation and generation of FXa by the extrinsic tenase complex (FVIIa.TF.FX). b Inhibition of FXa and FVIIa by TFPI. $\mathbf{c}$ Binding of the different Kunitz (K) domains by the various anti-TFPI antibodies.

The original article has been corrected.

The original article can be found online at https://doi.org/10.1007/ s40265-018-0922-6.

Pratima Chowdary

p.chowdary@ucl.ac.uk

1 Katharine Dormandy Haemophilia and Thrombosis Centre, Royal Free Hospital, Pond Street, London NW3 2 QG, UK 